\title{
Ligophorus species (Monogenea: Ancyrocephalidae) from Mugil cephalus (Teleostei: Mugilidae) off Morocco with the description of a new species and remarks about the use of Ligophorus spp. as biological markers of host populations
}

\author{
Fouzia El Hafidi ${ }^{1}$, Ouafae Berrada Rkhami ${ }^{2}$, Isaure de Buron ${ }^{3}$, Jean-Dominique Durand ${ }^{4}$ and Antoine \\ Pariselle $^{5}$ \\ ${ }^{1}$ Département de Biologie, Université Hassan II, Faculté des Sciences et Techniques de Mohammedia, Mohammedia, Morocco; \\ ${ }^{2}$ Laboratoire de Zoologie et de Biologie Générale, Université Mohammed V - Agdal, Faculté des Sciences, Rabat, Morocco; \\ ${ }^{3}$ Department of Biology, College of Charleston, Charleston, USA; \\ ${ }^{4}$ Institut de recherche pour le développement (IRD), Université Montpellier, Montpellier, France; \\ ${ }^{5}$ Institut de recherche pour le développement (IRD), ISE-M, Université Montpellier, Montpellier, France
}

\begin{abstract}
Gill monogenean species of Ligophorus Euzet et Suriano, 1977 were studied from the teleost Mugil cephalus Linneaus (Mugilidae) from the Mediterranean and Atlantic coasts of Morocco. We report the presence of L. mediterraneus from both the Mediterranean and Atlantic coast and L. cephali and L. maroccanus sp. n. from the Atlantic coast only. The latter species, which is described herein as new, resembles L. guanduensis but differs from this species mainly in having a shorter penis compared to the accessory piece, a proportionally longer extremity of the accessory piece and a less developed heel. The utility of Ligophorus spp. as markers of cryptic species of the complex $M$. cephalus is discussed in the context of species diversity and geographical distribution of these monogeneans on this host around the world. Presence of different species of Ligophorus on M. cephalus sensu stricto from the Atlantic and Mediterranean coast of Morocco demonstrates the usefulness of these species as fine resolution markers of genetic populations of their host, which are known to inhabit those coasts.
\end{abstract}

Keywords: Ligophorus maroccanus sp. n., cryptic species marker, geographical distribution, Atlantic Ocean, Mediterranean Sea

Ligophorus Euzet et Suriano, 1977 (Monogenea) belongs to the Ancyrocephalidae Bychowsky, 1937. Euzet and Suriano (1977) erected this genus with the type species L. vanbenedenii (Parona et Perugia, 1890) to describe parasites from gills of mugilids in the Mediterranean Sea. Euzet and Suriano (1977) described 11 species of Ligophorus, of which nine were new to science, all previously known as Ancyrocephalus vanbenedenii Parona et Perugia, 1890.

Since 1977, numerous species of Ligophorus have been described from different mugilid hosts around the world, which are generally specific of their host: from the Mediterranean Sea (Euzet and Sanfilippo 1983, D'Amelio et al. 1996), Black Sea (Sarabeev and Balbuena 2004, Sarabeev et al. 2005, Balbuena et al. 2006, Rubtsova et al. 2006, Dmitrieva et al. 2007), Pacific Ocean (Fernandez 1987), Atlantic Ocean (Fuentes and Nasir 1990, Abdallah et al. 2009, Faila Siquier and Ostrowski de Núñez 2009, Marcotegui and Martorelli 2009), Yellow Sea (Hu and Li 1992), Sea of Japan (Rubtsova et al. 2007), Red
Sea (Paperna and Overstreet 1981), Malacca Strait (Soo and Lim 2012) and the East and South China Seas (Zhang and Ji 1981, Pan 1999, Zhang et al. 2001, 2003). Today, there are 50 species of Ligophorus parasitising different species of mugilids and 17 of these are found on species making up the flathead mullet Mugil cephalus Linnaeus complex (see below).

Whereas M. cephalus was first described in the Mediterranean Sea off the coasts of Egypt, this species was later considered cosmopolitan. Recent genetic investigations on geographical populations of M. cephalus demonstrate the presence of cryptic species (Shen et al. 2011, Durand et al. 2012), phylogenetic relationships of which remain largely unknown (Whitfield et al. 2012).

In Morocco, the split of the coasts by the Strait of Gibraltar (Fig. 1) was shown to lead to the presence of genetically differentiated populations of the Mediterranean M. cephalus referred hereafter as M. cephalus sensu stricto (s.s.) on the Mediterranean and Atlantic coasts (Durand et al. 2013). 


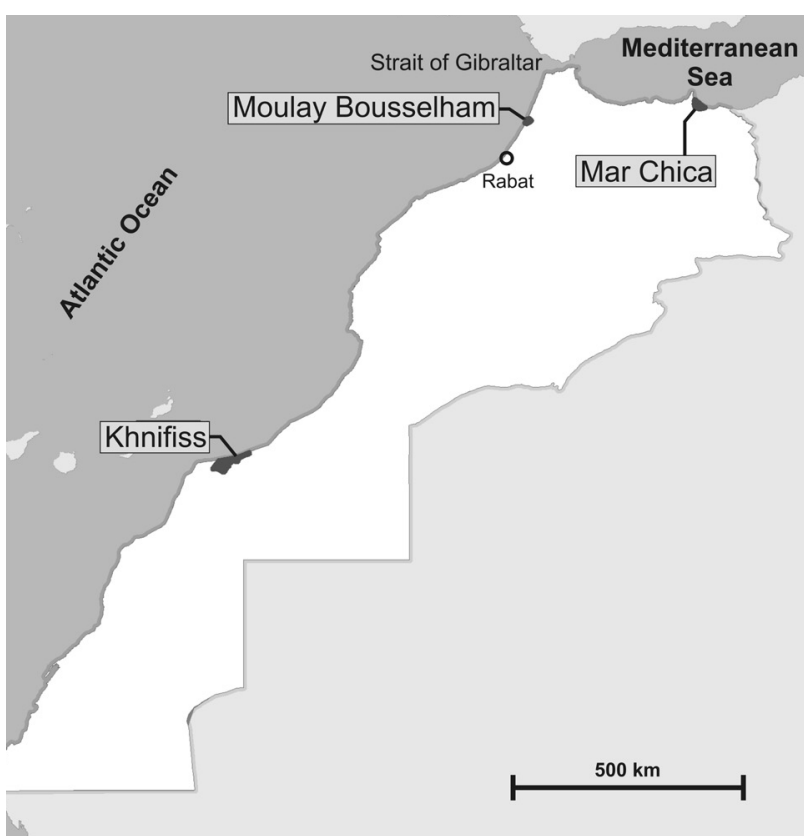

Fig. 1. Sampling localities in Morocco.

The monogeneans of $M$. cephalus are of particular interest because their oioxenous nature, i.e. strict host specificity, makes them good host population markers (see Pariselle et al. 2011 for review). Thus, gill monogeneans such as Ligophorus spp. may help determine the assemblage of cryptic species that constitute the M. cephalus sensu lato (s.1.) complex.

Therefore, this study had two goals: firstly, to report previously described Ligophorus species and describe a new one from $M$. cephalus s.s. from the coast of Morocco, and secondly to test whether the diversity of Ligophorus spp. on Moroccan flathead mullet reflects the finer scale population structure of $M$. cephalus s.s.

\section{MATERIALS AND METHODS}

Specimens of Mugil cephalus s.s. $(\mathrm{n}=120)$ were captured primarily in the lagoon of Moulay Bousselham (Atlantic Ocean: $\left.34^{\circ} 48^{\prime}-34^{\circ} 53^{\prime} \mathrm{N}, 6^{\circ} 14^{\prime}-6^{\circ} 18^{\prime} \mathrm{W}\right)$ from December 2008 to January 2010. Other specimens were captured from the Khnifiss Lagoon $(\mathrm{n}=30)$ (Atlantic Ocean: $27^{\circ} 57^{\prime}-28^{\circ} 03^{\prime} \mathrm{N}, 12^{\circ} 13^{\prime}-$ $\left.12^{\circ} 19^{\prime} \mathrm{W}\right)$ in March and September 2011 and from the Mar Chica $(n=13)$ (Mediterranean Sea: $35^{\circ} 06^{\prime}-35^{\circ} 15^{\prime} \mathrm{N}, 2^{\circ} 45^{\prime}-$ $2^{\circ} 56^{\prime} \mathrm{W}$ ) in January 2012. Moulay Bousselham, also known as Merja Zerga, is $35 \mathrm{~km}^{2}$, is located $120 \mathrm{~km}$ north of Rabat and it is the northernmost lagoon on the Moroccan Atlantic coast (Fig. 1). The Khnifiss Lagoon is the most important desert wetland in Morocco (6500 ha) and lies $900 \mathrm{~km}$ south of Rabat. The Mar Chica Lagoon, also called Nador Lagoon, is on the Mediterranean coast and is $22 \mathrm{~km}$ long and $6 \mathrm{~km}$ wide.

Several species of fish, including five species of Mugilidae belonging to three genera, live in sympatry in these three ecosystems: Mugil cephalus, Chelon labrosus (Risso), Liza ramada (Risso), L. aurata (Risso) and L. saliens (Risso). Fish, purchased from local fishermen shortly after they were captured, were identified and either dissected on site or kept on ice for about
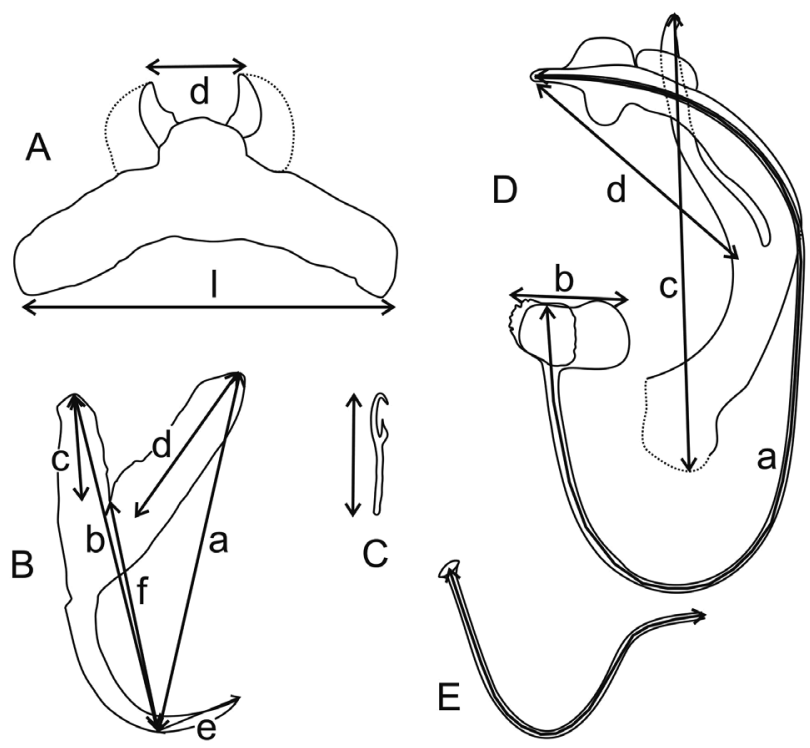

Fig. 2. Measurements of various sclerotized organs. A - ventral transverse bars: 1 - total length, $\mathrm{d}$ - distance between expansions; $\mathbf{B}$ - anchor: $\mathrm{a}$ - total length, $\mathrm{b}$ - distance shaft-point, $\mathrm{c}$ - shaft length, $\mathrm{d}$ - guard length, e - point length, $\mathrm{f}$ - blade length; $\mathbf{C}$ - hook; $\mathbf{D}$ - male copulatory organ (MCO): a - penis total length, $\mathrm{b}$ - bipartite base length, $\mathrm{c}$ - accessory piece length, $\mathrm{d}$ - extremity of accessory piece length; $\mathbf{E}$ - vagina total length.

24 hours prior to freezing upon return to the laboratory. Gill arches were separated and placed individually in Petri dishes.

Monogeneans were collected according to procedures described by Pariselle and Euzet (1994). Worms were mounted either in Malmberg's (Malmberg 1957) or in Berlèse's medium and sealed with Glyceel (see Bathes 1997). Worms were observed at $400 \times$ and $1000 \times$ using a compound microscope. Terminology and numbering of the haptor parts are those adopted at ICOPA IV (Euzet and Prost 1981). Measurements were taken from mounted specimens using a Leica 2500 compound microscope equipped with a Leica DFC 320 digital camera using LAS 3.1 software (Fig. 2). All measurements are in micrometres and expressed as follows: mean \pm standard deviation with minimum-maximum value and number of observations in paratheses. Micrographs were taken using a Reichert-Jung Polyvar compound microscope at $1000 \times$ magnification using interference phase contrast. The material was deposited at the Musée National d'Histoire Naturelle de Paris (MNHN).

\section{RESULTS}

No Ligophorus specimens were found in any of the 30 flathead mullets dissected from Khnifiss Lagoon. However, L. mediterraneus was found from Moulay Bousselham and Mar Chica lagoons. Ligophorus cephali and a new species, L. maroccanus sp. n., were found from fish collected from Moulay Bousselham Lagoon only.

Ligophorus mediterraneus Sarabeev, Balbuena et Euzet, 2005

Fig. 3 A,C

Redescription. Body $791 \pm 7(780-800 ; n=7)$ long and $120 \pm 1(119-121 ; \mathrm{n}=7)$ wide at level of ovary. Mouth opening ventral. Pharynx ovoid, $37 \pm 0.4$ (37-38; 

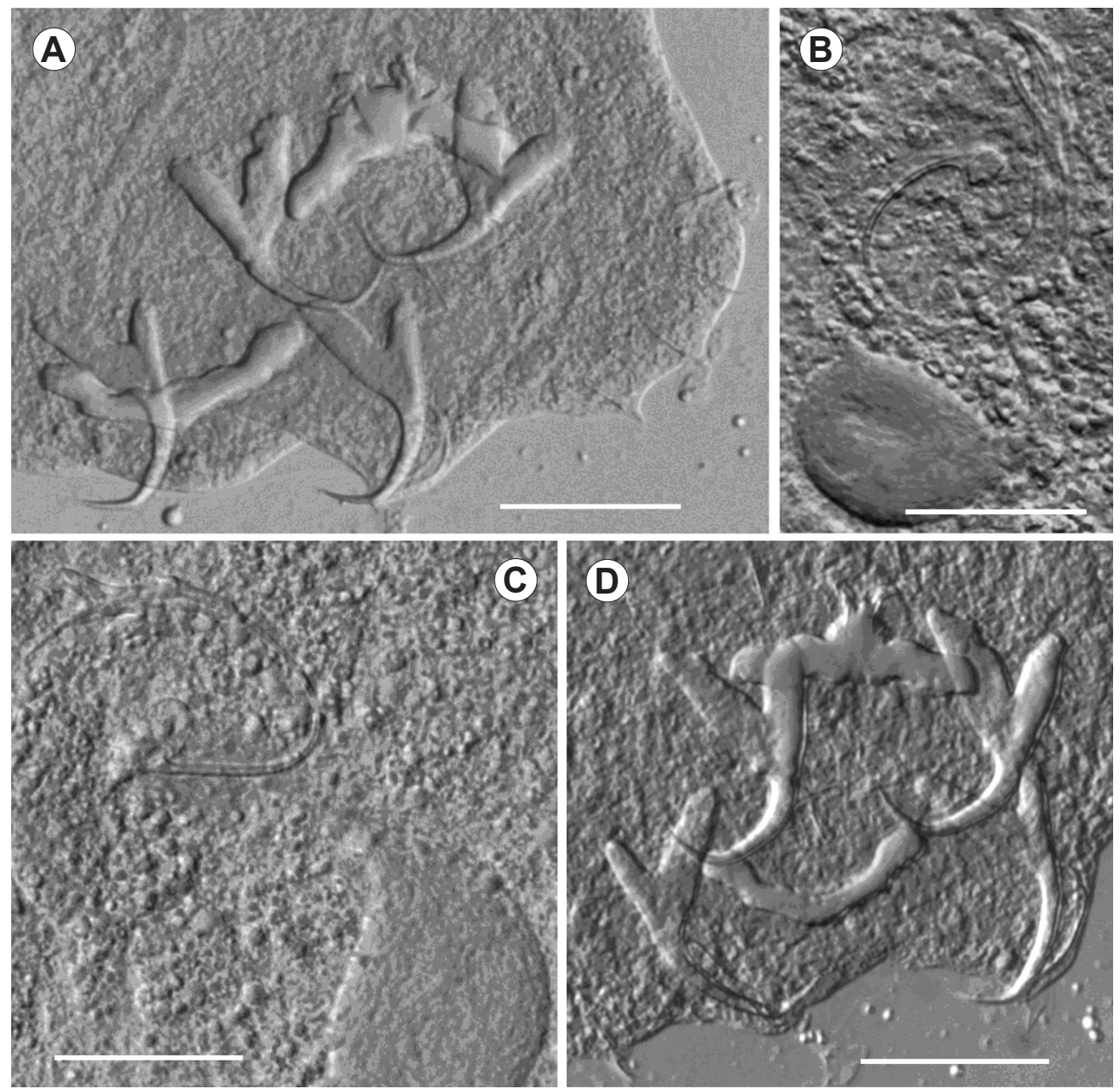

Fig. 3. A - Ligophorus mediterraneus - haptor; B - Ligophorus cephali-male copulatory organ; C - Ligophorus mediterraneus male copulatory organ; D - Ligophorus cephali - haptoral sclerites. Scale bars $=30 \mu \mathrm{m}$.

$\mathrm{n}=8$ ) in diameter, followed by short oesophagus; digestive tract divided in two branches joined posteriorly.

Haptor with 14 hooks, $13 \pm 0.2(13-14 ; \mathrm{n}=7)$ long, four anchors and two transverse bars. Ventral bar slightly curved, thick at middle, with two median anterior expansions close together, $41 \pm 1(38-42 ; \mathrm{n}=12)$ long, expansions at $10 \pm 2(7-12 ; \mathrm{n}=12)$ from each other. Dorsal bar slightly arched, with rounded extremities, $40 \pm 2$ (34-43; $\mathrm{n}=12$ ) long.

Ventral and dorsal anchors similar in shape and size, ventral with guard and shaft almost equal in length: a: $36 \pm 2(31-41 ; \mathrm{n}=24) ; \mathrm{b}: 34 \pm 2(29-37 ; \mathrm{n}=24) ; \mathrm{c}$ : $12 \pm 2(9-15 ; \mathrm{n}=24) ; \mathrm{d}: 16 \pm 2(12-21 ; \mathrm{n}=24) ;$ e: $9 \pm 1$ $(7-11 ; \mathrm{n}=24) ; \mathrm{f}: 19 \pm 2(16-22 ; \mathrm{n}=24)$. Dorsal anchor with shaft shorter than guard: a: $34 \pm 2(30-38 ; n=24)$; : $33 \pm 1(31-35 ; \mathrm{n}=24) ; \mathrm{c}: 10 \pm 2(7-14 ; \mathrm{n}=24) ; \mathrm{d}: 14 \pm 2$ $(11-16 ; n=24)$; e: $9 \pm 1(7-11 ; n=24) ; f: 18 \pm 2(11-23$, $\mathrm{n}=24)$.

Vagina tubular, sclerotized, $47 \pm 11(30-64 ; \mathrm{n}=12)$ long, with enlarged mid-ventral aperture. Male copulatory organ (MCO) with long and narrow penis, a: $99 \pm 5$ (92-107, $\mathrm{n}=12)$, beginning by expanded bipartite base, b: $10 \pm 1(8-12 ; n=12)$ long, going through accessory piece, c: $37 \pm 4(31-45 ; n=12)$ long, which ends in rounded claw.

H o st: Mugil cephalus Linnaeus (Mugilidae).

Localities: Lagoons of Moulay Bousselham (Atlantic Ocean) (prevalence $90 \%$ ) and Mar Chica (Mediterranean Sea) (prevalence $100 \%$ ), Morocco.

Site: Gills.

Material examined: 12 adult specimens mounted in Malmberg's medium (glycerin amonium picrate, GAP).

Ligophorus cephali Rubtsova, Balbuena, Sarabeev, Blasco-Costa et Euzet, 2006

Fig. 3 B,D

Redescription. Body $979 \pm 38(930-1020 ; \mathrm{n}=5)$ long and $125 \pm 5(119-130 ; \mathrm{n}=5)$ wide at level of ovary. Mouth opening ventral. Pharynx $36 \pm 0.4(35-37 ; n=8)$ in diameter. Oesophagus short, divided in two branches joined posteriorly.

Haptor with 14 hooks, $14 \pm 0.3(13-14 ; \mathrm{n}=5)$ long, and four anchors with two transverse bars equal in length. Ventral bar slightly curved, $36 \pm 2(31-39 ; \mathrm{n}=32)$ long, with two expansions in middle, $8 \pm 2(5-10 ; \mathrm{n}=32)$ apart 

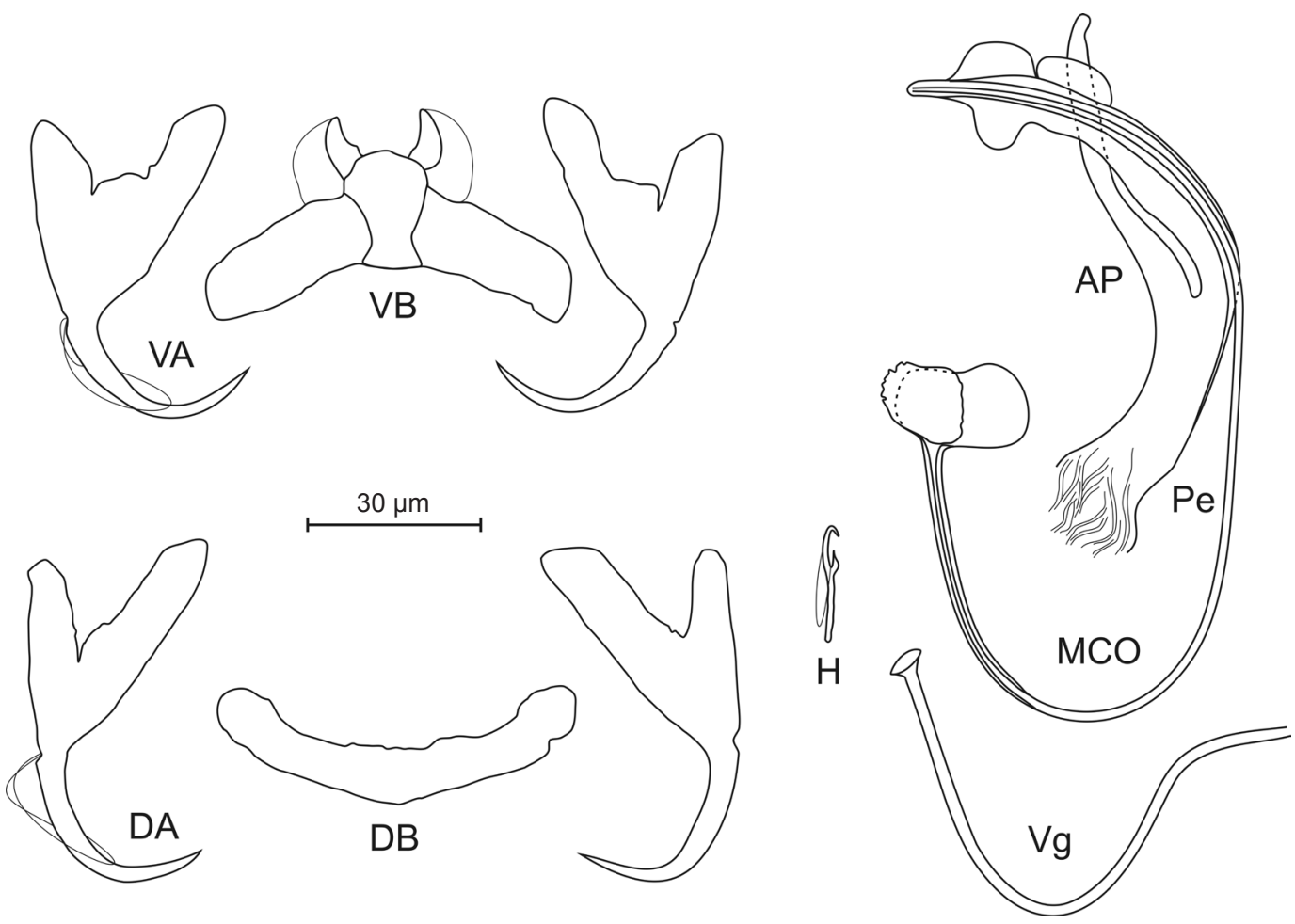

Fig. 4. Ligophorus maroccanus sp. n. from Mugil cephalus Linnaeus. Abbreviations: AP - accessory piece; DA - dorsal anchor; DB - dorsal bar; H - hook; MCO - male copulatory organ; Pe - penis; VA - ventral anchor; VB - ventral bar; Vg - vagina.

from each other. Dorsal bar slightly curved, with irregular edge, $36 \pm 2(32-42 ; n=32)$ long.

Dorsal and ventral anchors nearly equal. Ventral anchor with shaft shorter and narrower than guard: a: $37 \pm 2$ $(26-41 ; \mathrm{n}=64) ; \mathrm{b}: 36 \pm 2(31-39 ; \mathrm{n}=64) ; \mathrm{c}: 11 \pm 2(7-15$; $\mathrm{n}=64) ; \mathrm{d}: 17 \pm 3(8-23 ; \mathrm{n}=63)$; e: $10 \pm 1(8-12 ; \mathrm{n}=64)$; f: $20 \pm 2(16-25 ; n=64)$. Dorsal anchor with shaft shorter than guard: a: $37 \pm 1(34-40 ; \mathrm{n}=64) ; \mathrm{b}: 37 \pm 2(31-40$; $\mathrm{n}=64)$; $\mathrm{c}: 9 \pm 2(6-14 ; \mathrm{n}=64) ; \mathrm{d}: 15 \pm 2(10-19 ; \mathrm{n}=64)$; e: $9 \pm 1(7-11 ; \mathrm{n}=64)$; f: $21 \pm 2(15-26 ; \mathrm{n}=64)$.

Vagina sinuous, tubular, $49 \pm 15(20-70 ; \mathrm{n}=32)$ long, with enlarged aperture. Ovary U-shaped. MCO with long and narrow penis, a: $105 \pm 8(83-119 ; \mathrm{n}=32)$, beginning by expanded bipartite base, $\mathrm{b}: 10 \pm 1(7-12 ; \mathrm{n}=32)$ long; accessory piece bifurcated, c: $42 \pm 5(32-52 ; \mathrm{n}=32)$ total length, extremity, d: $26 \pm 3(19-31 ; \mathrm{n}=32)$ long.

Host: Mugil cephalus Linnaeus (Mugilidae).

L o c a lity: Lagoon of Moulay Bousselham (Atlantic Ocean), Morocco (prevalence 65\%).

Site: Gills.

Material examined: 32 adult specimens mounted in Malmberg medium.

Ligophorus maroccanus El Hafidi, Berrada Rkhami et Pariselle sp. n.

Figs. 4, 5

Description. Ancyrocephalidae. Body $1048 \pm 120$ $(865-1257 ; \mathrm{n}=16)$ long and $174 \pm 26(124-220 ; \mathrm{n}=16)$ wide at level of ovary. Body dorsoventrally flattened, an- terior part with developed median and two lateral cephalic lobes. Four symmetrical eyespots present. Mouth opening ventral. Pharynx $53 \pm 9(42-69 ; n=14)$ in diameter, followed by short oesophagus, divided in two unbranched lateral branches, joined posteriorly.

Haptor with 14 hooks, $14 \pm 0.5(13-14 ; \mathrm{n}=9)$ long. Ventral transverse bar open V-shaped, $41 \pm 3$ (35-47; $\mathrm{n}=31$ ) long, with rounded thickening at middle and two anterior expansions, $10 \pm 2(8-14 ; n=30)$ apart from each other. Ventral anchor with shaft shorter and wider than guard, latter with enlargement step-shaped at middle, and short blade: a: $36 \pm 2(33-40 ; n=63) ; b: 35 \pm 3(31-41$; $\mathrm{n}=63) ; \mathrm{c}: 12 \pm 2(7-16 ; \mathrm{n}=63) ; \mathrm{d}: 17 \pm 3(12-23 ; \mathrm{n}=63)$; e: $10 \pm 1(8-12 ; n=63)$; f: $17 \pm 2(14-24 ; n=63)$. Dorsal transverse bar open V-shaped, with irregular edges and rounded extremities, $41 \pm 3(35-50 ; \mathrm{n}=32)$ long. Dorsal anchor with shaft shorter and narrower than guard, short blade bent at $90^{\circ}$ at junction with point: a: $36 \pm 2$ $(32-43 ; \mathrm{n}=64) ; \mathrm{b}: 36 \pm 3(31-42 ; \mathrm{n}=64) ; \mathrm{c}: 10 \pm 2$ $(7-15 ; \mathrm{n}=64) ; \mathrm{d}: 16 \pm 2(10-21 ; \mathrm{n}=64) ; \mathrm{e}: 10 \pm 1(7-11$; $\mathrm{n}=64) ; \mathrm{f}: 18 \pm 1(15-21 ; \mathrm{n}=64)$.

Vagina tubular, with sclerotized walls, $74 \pm 13$ (41-96; $\mathrm{n}=32$ ) long, and irregularly enlarged mid-ventral aperture, $14 \pm 4(8-20 ; n=10)$ in diameter. MCO with long and narrow penis a: $140 \pm 5(130-153 ; \mathrm{n}=32)$, beginning by expanded bipartite base, b: $12 \pm 1(9-14 ; \mathrm{n}=32)$ long; accessory piece, c: $76 \pm 5(66-87 ; \mathrm{n}=32)$ total length, extremity bifurcated, represents half total length of acces- 

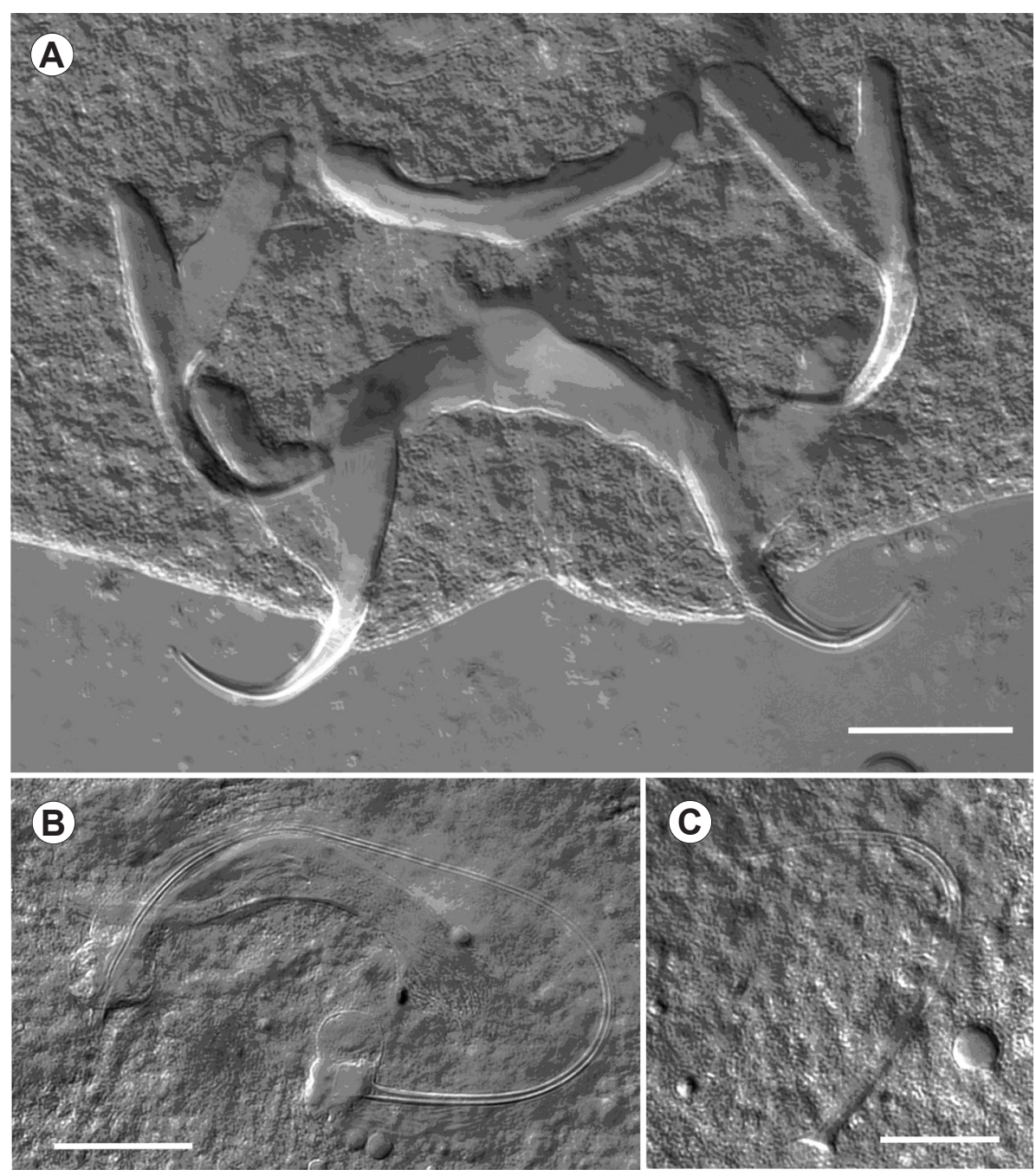

Fig. 5. Ligophorus maroccanus sp. n. Interference phase contrast: $\mathbf{A}$ - haptor; $\mathbf{B}$ - male copulatory organ; $\mathbf{C}$ - vagina. Scale bars: $\mathrm{A}, \mathrm{B}=20 \mu \mathrm{m} ; \mathrm{C}=10 \mu \mathrm{m}$.

sory piece, $\mathrm{d}: 40 \pm 4(32-49 ; \mathrm{n}=32)$ long, one branch thin, the other bulbous at its extremity, crossed or parallel.

Type host: Mugil cephalus Linnaeus (Mugilidae).

Type locality: Lagoon of Moulay Bousselham (Atlantic Ocean), Morocco $\left(34^{\circ} 48^{\prime}-34^{\circ} 53^{\prime} \mathrm{N}, 6^{\circ} 14^{\prime}-6^{\circ} 18^{\prime} \mathrm{W}\right)$, December 2008 to January 2010 (prevalence $68 \%$ ).

Site: Gills.

Type material: Holotype in MNHN (Coll. No. HEL317); paratypes in MNHN (HEL318), collected in September 2009.

Material examined: 32 adult specimens mounted in Malmberg's medium and 7 in Berlèse's medium.

Ety mology: The epithet maroccanus is given according to the origin of the newly described species.

Remarks. This species is placed in Ligophorus based on the morphological characteristics described by Euzet and Suriano (1977): it has a fusiform body, a haptor armed with 14 hooks, two pairs of anchors and two (one dorsal and one ventral) transverse bars; digestive branches without diverticles, joined posteriorly; vas deferens does not loop around the right intestinal branch, one prostatic vesicle; vagina opens medioventrally. According to Mariniello et al. (2004), Ligophorus species are identified according to the morphology and the size of the sclerotized parts of the genitalia and the haptor.

Comparisons of the biometric and morphological parameters of the newly described species with those for 50 other species known to date, and in particular with the 17 described from the same host species (see below), showed conspicuous differences. Ligophorus maroccanus differs from its three congeners found on M. cephalus s.s. by the size and the shape of sclerotized parts of the MCO: penis is $140 \mu \mathrm{m} v s$ 105, 99 and $110 \mu \mathrm{m}$ and accessory piece is $76 \mu \mathrm{m} v s 42,37$ and $34 \mu \mathrm{m}$ for L. cephali, L. mediterraneus and L. chabaudi, respectively. Moreover, the accessory piece is bifurcated with one rounded extremity in L. maroccanus, whereas no rounded extremities are present in L. chabaudi and L. cephali, and no bifurcated extremity in L. mediterraneus. Only L. guanduensis Abdallah, de Azevedo et Luque, 2009, found on Mugil liza 
Valenciennes from the Guandu River in Brazil (see below) has sclerotized parts of MCO and haptor that morphologically resemble those of $L$. maroccanus sp. n. However, most components of these organs are of different size in the two species: e.g. penis length: 126-129 $\mu \mathrm{m} v s$ 130-153 $\mu \mathrm{m}$ (L. guanduensis vs L. maroccanus); accessory piece total length: $56-64 \mu \mathrm{m} v s$ 66-87 $\mu \mathrm{m}$; ventral bar length: 55-58 $\mu \mathrm{m}$ vs 35-47 $\mu \mathrm{m}$; distance between anterior expansions: 5-6 $\mu \mathrm{m} v s$ 8-14 $\mu \mathrm{m}$; ventral anchor total length: 43-47 $\mu \mathrm{m} v s$ 33-40 $\mu \mathrm{m}$; dorsal bar length: 56-63 $\mu \mathrm{m} v s$ 35-50 $\mu \mathrm{m}$ and dorsal anchor total length: 41-43 $\mu \mathrm{m} v s$ $32-43 \mu \mathrm{m}$. The three major differences are the ratio of the length of the penis to the total length of accessory piece (2.1 vs 1.8), ratio of the length of the extremity to the total length of the accessory piece $(0.44 v s 0.53)$ and the size of the heel (more developed in L. guanduensis).

\section{DISCUSSION}

The new species described herein is the 18th Ligophorus species described from Mugil cephalus s.l. (see below). This diversity is much higher than that reported for other species of the Mugilidae, which otherwise have a maximum of six species on Liza carinata Valenciennes (see Dmitrieva et al. 2012) or Liza subviridis Valenciennes (see Soo and Lim 2012). A literature review of the distribution of Ligophorus spp. from M. cephalus s.l. shows that, as already reported, these species are generally specific of their host from each geographical population:

(i) South Pacific Ocean (Fig. 6 - entity 3): L. huitrempe Fernandez, 1987;

(ii) Northwest Atlantic Ocean (Fig. 6 - entity 4): L. mugilinus;

(iii) Southwest Atlantic Ocean (Fig. 6 - entity 5): L. brasiliensis Abdallah, de Azevedo et Luque, 2009; L. guanduensis; L. lizae Abdallah, de Azevedo et Luque, 2009; L. tainhae Abdallah, de Azevedo et Luque, 2009, all from Mugil liza (which is, according to Heras et al. 2009 and Durand et al. 2012, part of the M. cephalus species complex); L. saladensis Marcotegui et Martorelli, 2009; and L. uruguayense Failla Siquier et Ostrowski de Núñez, 2009 from Mugil platanus Günther (which is, according to Fraga et al. 2007, Heras et al. 2009 and Durand et al. 2012, synonymous with $M$. liza, i.e. part of the $M$. cephalus complex - see above);

(iv) Mediterranean Sea, Black Sea and Eastern Atlantic Ocean (Fig. 6 - entity 8): L. cephali, L. chabaudi, L. mediterraneus and L. maroccanus sp. n.;

(v) Sea of Japan (Fig. 6-entity 13): L. cheleus Rubtsova, Balbuena et Sarabeev, 2007; L. domnichi Rubtsova, Balbuena et Sarabeev, 2007; L. pacificus Rubtsova, Balbuena et Sarabeev, 2007; and L. chabaudi Euzet et Suriano, 1977;

(vi) Yellow Sea (China/Korea) (Fig. 6 - entity 14): L. chenzhensensis $\mathrm{Hu}$ et Li, 1992 and L. chongmingensis $\mathrm{Hu}$ et $\mathrm{Li}, 1992$; (vii) East and South China seas (China) (Fig. 6 - entity 14): L. leporinus (Zhang et Ji, 1981) Gussev, 1985; L. mugilinus (Hargis, 1955) Euzet et Suriano, 1977; and L. pacificus.

No parasitological data are available for other entities of M. cephalus s.l.

Only two Ligophorus species are reported from two geographically distant host populations: L. chabaudi from the Sea of Japan (entity 13) and the Mediterranean Sea (entity 8), and L. mugilinus from the East and South China Seas (entity 14) and the Northwestern Atlantic Ocean (entity 4) (see Fig. 6, Zhang et al. 2003, Dmitrieva et al. 2009). Ligophorus pacificus is found on hosts from entities 13 and 14 that are sympatric.

The unusually high diversity of Ligophorus species from $M$. cephalus may be a reflection of the combined facts that these monogeneans have an oioxenous specificity for their hosts and that $M$. cephalus is now recognized to be either a group of cryptic species or a genetically well differentiated set of populations (Durand et al. 2012, Whitfield et al. 2012; Fig. 6). Thus, this supports the idea that different species of Ligophorus infect the different 'species' that comprise the $M$. cephalus complex, but which are themselves yet to be identified.

As an illustration, $M$. liza, now recognized to be part of the M. cephalus s.l. species complex, is infected by six species of Ligophorus (including parasites of M. platanus populations, see above) found only on this host. Therefore, this indicates that Ligophorus spp. may be useful markers of cryptic $M$. cephalus s.l. species. Furthermore, since there is no contact between host populations, the presence of $L$. chabaudi and L. mugilinus on two distant host entities indicates that these parasites may be two cryptic species that originate from the ancestral $M$. cephalus host species. Neither possibility is in contradiction with our hypothesis.

Our results also support the assumption that Ligophorus species may serve as good host markers at a smaller scale. In fact, Mugil cephalus s.s., which is found in the Mediterranean Sea, Black Sea and Eastern Atlantic Ocean from Bordeaux (France) to the lagoon of Khnifiss (Morocco) (Fig. 6, entity 8), displays in Morocco two genetically differentiated populations separated by the Gibraltar Strait (Durand et al. 2013): one along the Atlantic coasts and the other along the Mediterranean coasts (see above).

Whereas $M$. cephalus s.s. is infected by $L$. cephali and L. mediterraneus throughout its distribution area (Sarabeev et al. 2005, Rubstova et al. 2007) including the Moroccan Atlantic coasts (present study), we found L. maroccanus sp. n. only from the Atlantic Ocean coasts of Morocco (and not from the Mediterranean coasts), likewise L. chabaudi, described from the Mediterranean Sea (Euzet and Suriano 1977), was not found along the Atlantic coast of Morocco despite the substantial number of hosts examined. Thus, L. maroccanus and L. chabaudi 


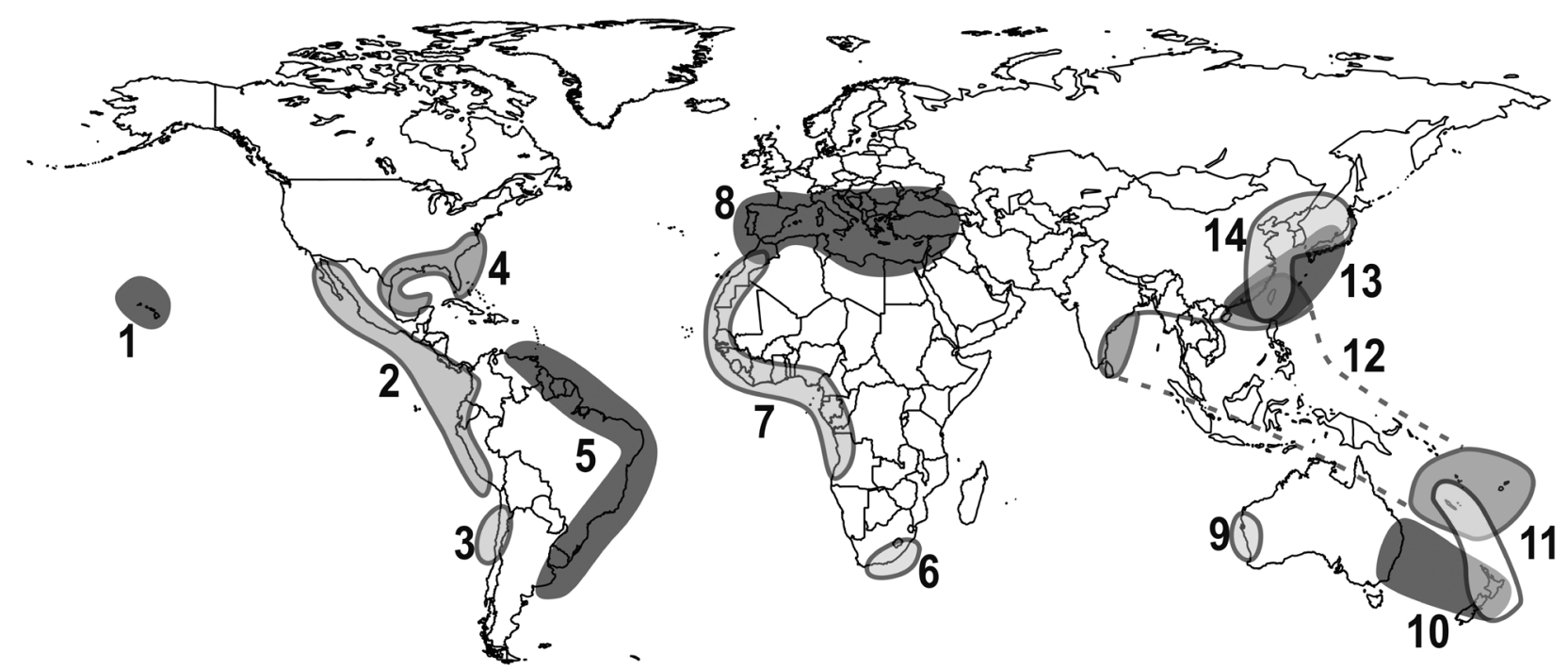

Fig. 6. Genetically differentiated entities within Mugil cephalus sensu lato after Whitefield et al. (2012). Abbreviations: 1 - Hawaii; 2 - Central East Pacific; 3 - Southern East Pacific; 4 - Western North Atlantic; 5 - Western Central Atlantic; 6 - Southern Africa; 7 - Western Africa; 8 - Mediterranean Sea; 9 - Western Australia; 10 - South Eastern Australia; 11 - Western Pacific; 12 - Central Western Pacific and North West Indian Ocean; 13, 14 - Sea of Japan, Yellow Sea and East China Sea.

may be considered as good markers for the Atlantic and Mediterranean population of M. cephalus s.s., respectively.

Similarly, L. tainhae, L. brasiliensis, L. guanduensis and L. lizae parasitise the northern populations of M. liza (part of the complex M. cephalus s.1.), whereas L. uruguayense and L. saladensis are described only from southern populations of the same fish species (M. platanus, syn. M. liza), thus further supporting the idea that Ligophorus species are good markers of Mugil cephalus populations in general.

The absence of Ligophorus spp. on M. cephalus from the Khnifiss Lagoon, which is the southern limit of the host's distribution area (Whitfield et al. 2012; Fig. 6 - entity 8 ) could be associated to local environmental factors (e.g. salinity or temperature) as has been shown for other monogeneans (e.g. Diggles et al. 1993, Gannicot and Tinsley 1998) and was suspected to be the case for other gill monogeneans of M. cephalus s.l. by Baker et al. (2008). Alternatively, the populations situated at the edge of their distributional range may present fewer parasites due to founder or bottleneck events (Pariselle et al. 2003).

Acknowledgments. The authors thank A. Benhoussa and H. Bazairi (Faculty of Sciences Mohammed V - Agdal, Rabat, Morocco) for their assistance in fish collection, V.A. Connors (University of South Carolina Upstate, SC, USA) for his assistance in text translation, and L. Euzet (Université de Montpellier, France) for insightful discussions about mugilid monogeneans. Funding for fish collection was provided in part by the College of Charleston, USA.

\section{REFERENCES}

Abdallah V.D., De Azevedo R.K., Luque J.L. 2009: Four new species of Ligophorus (Monogenea: Dactylogyridae) parasitic on Mugil liza (Actinopterygii: Mugilidae) from Guandu River, southeastern Brazil. J. Parasitol. 95: 855-864.

Baker T.G., Pante E., Levesque E.M, Roumillat W.A., De BURon I. 2008: Metamicrocotyla macracantha, a polyopisthocotylid gill parasite of the stripped mullet, Mugil cephalus: population dynamics in South Carolina estuaries. Parasitol. Res. 102: 1085-1088.

Balbuena J.A., Rubtsova N.Y., Sarabeev V.L. 2006: Ligophorus pilengas Sarabeev \& Balbuena, 2004 (Monogenea: Ancyrocephalidae) is proposed as the senior synonym of $L$. gussevi Miroschnicenko et Maltsev, 2004. Syst. Parasitol. 63: 95-98.

Bates J.W. 1997: The slide-sealing compound "Glyceel". J. Nematol. 29: $565-566$

D’Amelio S., Di Cave D., Orecchia P., Paggi L. 1996: Le communità dei metazoi parassiti di Liza ramada (Risso, 1826) (Pi- sces: Mugilidae) nei laghi di Sabaudia (LT) e del Fusaro (NA). Suppl. Ric. Biol. Selvaggina 24: 671-676.

Diggles B.K., Roubal F.R., Lester R.J.G. 1993: Effects of formalin, benzocaine and hyposalinity on the fecundity and variability of Polylabroides multispinosus (Monogenea: Microcotylidae) parasitic on the gills of Acanthopargrus australis (Pisces, Sparidae). Int. J. Parasitol. 23: 877-884.

Dmitrieva E.V., Gerasev P.I., Gibson D.I., Pronkina N.V., GALLI P. 2012: Descriptions of eight new species of Ligophorus Euzet \& Suriano, 1977 (Monogenea: Ancyrocephalidae) from Red Sea mullets. Syst. Parasitol. 81: 203-237.

Dmitrieva E.V., Gerasev P.I., Merella P., Pugachev O.N. 2009: Redescriptions of Ligophorus cephali Rubtsova, Balbuena, Sarabeev, Blasco-Costa et Euzet, 2006 and L. chabaudi Euzet et Suriano, 1977 (Monogenea: Ancyrocephalidae), with notes on the functional morphology of the copulatory organ. Syst. Parasitol. 73: 175-191. 
Dmitrieva E.V., Gerasev P.I., Pron'Kina N.V. 2007: Ligophorus llewellyni n. sp. (Monogenea: Ancyrocephalidae) from the redlip mullet Liza haematocheilus (Temminck et Schlegel) introduced into the Black Sea from the Far East. Syst. Parasitol. 67: 51-64.

Durand J.-D., Blel H., Shen K.-N., Koutrakis E.T., Guinand B. 2013: Population genetic structure of Mugil cephalus in the Mediterranean and Black Seas: a single mitochondrial clade, many nuclear barriers. Mar. Ecol. Pro. Ser. 474: 243-261.

Durand J.-D., Shen K.-N., Chen W.-J., Jamandre B.W., Blel H., Diop K., Nirchio M., García De León F.J., Whitfield A.K., Chang C.-W., Borsa P. 2012: Systematics of the grey mullets (Teleostei: Mugiliformes: Mugilidae): molecular phylogenetic evidence challenges two centuries of morphologybased taxonomic studies. Mol. Phyl. Evol. 64: 73-92.

Euzet L., Prost M. 1981: Report of the meeting on Monogenea: problems of systematics, biology and ecology. In: W. Slusarski (Ed.), Review of Advances in Parasitology. P.W.N. Polish Scientific Publishers, Warsaw, pp. 1003-1004.

Euzet L., Sanfilippo D. 1983: Ligophorus parvicirrus n. sp. (Monogenea: Ancyrocephalidae) parasite de Liza ramada (Risso, 1826) (Teleostei, Mugilidae). Ann. Parasitol. Hum. Comp. 58: $325-335$.

Euzet L., Suriano D.M. 1977: Ligophorus n. g. (Monogenea: Ancyrocephalidae) parasite des Mugilidae (Téléostéens) en Méditerranée. Bull. Mus. Nat. Hist. Nat., Ser. 3, Zool. 472: 799-821.

Fernandez J. 1987: Los parásitos de la lisa Mugil cephalus L., en Chile: sistemática y aspectos poblacionales (Perciformes: Mugilidae). Gay. Zool. 51: 3-58.

Failla Siquier G., Ostrowski de Nuñez M. 2009: Ligophorus uruguayense sp. nov. (Monogenea, Ancyrocephalidae), a gill parasite from Mugil platanus (Mugiliformes, Mugilidae) in Uruguay. Acta Parasitol. 54: 95-102.

Fraga E., Schneider H., Nirchio M., Santa-Brigida E., RoDRigues-Filho L.F., Sampaio I. 2007: Molecular phylogenetic analyses of mullets (Mugilidae, Mugiliformes) based on two mitochondrial genes. J. Appl. Ichthyol. 23: 598-604.

Fuentes J.L., Nasir P. 1990: Descripción y ecología de Ligophorus mugilinus (Hargis, 1955) Euzet y Suriano, 1977 (Monogenea: Ancyrocephalinae) en Mugil curema (Val. 1936) de la Isla de Margarita, Venezuela. Scient. Mar. 54: 187-193.

Gannicot A.M., Tinsley R.C. 1998: Environmental effects on transmission of Discocotyle sagitta (Monogenea): egg production and development. Parasitology 117: 499-504.

Heras S., Roldan M.I., Gonzalez Castro M. 2009: Molecular phylogeny of Mugilidae fishes revised. Rev. Fish Biol. Fish. 19: 217-231.

Hu Z., Li D. 1992: [Two new species of monogenetic trematodes of marine fishes Mugil cephalus from the Chongming Island, Shanghai, China]. J. Shang. Teach. Univ. (Nat. Sci.). 21: 67-70. (in Chinese.)

Malmberg G. 1957: On the occurrence of Gyrodactylus on Swedish fishes. Skrift. Sod. Sver. Fiskerif. 20: 19-76.

Marcotegui P.S., Martorelli S.R. 2009: Ligophorus saladensis n. sp. (Monogenea: Ancyrocephalidae) from Mugil platanus Gunther in Samborombon Bay, Argentina. Syst. Parasitol. 74: 41-47.

Mariniello L., Ortis M., D’Amelio S., Petrarca V. 2004: Morphometric variability between and within species of Ligophorus Euzet \& Suriano, 1977 (Monogenea: Ancyrocephalidae) in the Mediterranean Sea. Syst. Parasitol. 57: 183-190.
PAN J. 1999: Monogenea of marine fishes from Hainan Island V. One new species of the genus Ligophorus from the South China Sea. Zool. Res. 20: 186-188.

Paperna I., Overstreet R.M. 1981: Parasite and diseases of Mullets (Mugilidae). In: O.H. Oren, (Ed.), Aquaculture of Grey Mullets. IBP 26, Cambridge University Press, U.K. pp 411-493.

Pariselle A., Boeger W.A., Snoeks J., Bilong Bilong C.F., Morand S., Vanhove M.P.M. 2011: The monogenean parasite fauna of cichlids: a potential tool for host biogeography. Int. J. Evol. Biol. 2011: 471480.

Pariselle A., Euzet L. 1994: Three new species of Cichlidogyrus Paperna, 1960 (Monogenea, Ancyrocephalidae) parasitic on Tylochromis jentinki (Steindachner, 1895) (Pisces, Cichlidae) in West Africa. Syst. Parasitol. 29: 229-234.

Pariselle A., Morand S., Deveney M., Pouyaud L. 2003: Parasite species richness of closely related hosts: historical scenario and "genetic" hypothesis. In: C. Combes and J. Jourdane (Eds.), Taxonomy, Ecology and Evolution of Metazoan Parasites. Livre hommage à Louis Euzet. Volume 2. PUP, Perpignan, pp. $147-166$.

Rubtsova N.Y., Balbuena J.A., Sarabeev V.L. 2007: Three new species of Ligophorus (Monogenea: Dactylogyridae) on the gills of Mugil cephalus (Teleostei: Mugilidae) from the Japan Sea. J. Parasitol. 93: 772-780.

Rubtsova N.Y., Balbuena J.A., Sarabeev J.L., Blasco I., EuZET L. 2006: Description and morphometrical variability of a new species of Ligophorus and of Ligophorus chabaudi (Monogenea: Dactylogyridae) on Mugil cephalus (Teleostei) from the Mediterranean Basin. J. Parasitol. 92: 486-495.

Sarabeev V.L., Balbuena J.A. 2004: Ligophorus pilengas $\mathrm{n}$. $\mathrm{sp}$. (Monogenea: Ancyrocephalidae) from the introduced so-ioy mullet, Mugil soiuy (Teleostei: Mugilidae), in the Sea of Azov and the Black Sea. J. Parasitol. 90: 222-228.

Sarabeev V.L., Balbuena J.A., Euzet L. 2005: Taxonomic status of Ligophorus mugilinus (Hargis, 1955) (Monogenea: Ancyrocephalidae), with a description of a new species of $\mathrm{Li}$ gophorus from Mugil cephalus (Teleostei: Mugilidae) in the Mediterranean basin. J. Parasitol. 91: 1444-1451.

Shen K.-N., Jamandre B.W., Hsu C.-C., Tzeng W.-N., DuRAND J.-D. 2011: Plio-Pleistocene sea level and temperature fluctuations in the northwestern Pacific promoted speciation in the globally-distributed flathead mullet Mugil cephalus. BMC Evol. Biol. 11: 83.

Soo O.Y.M., Lim L.H.S. 2012: Eight new species of Ligophorus Euzet et Suriano, 1977 (Monogenea: Ancyrocephalidae) from mugilids off peninsular Malaysia. Raff. Bul. Zool. 60: 241-264.

Whitfield A.K., Panfili J., Durand J.-D. 2012: A global review of the cosmopolitan flathead mullet Mugil cephalus Linnaeus 1758 (Teleostei: Mugilidae), with emphasis on the biology, genetics, ecology and fisheries aspects of this apparent species complex. Rev. Fish Biol. Fish. 22: 641-681

ZHANG J., JI G. 1981: [Monogenetic trematodes of Chinese marine fishes: two new species of Ancyrocephalus from the gills of Mugil cephalus, description of a new species]. Oceanol. Limnol. Sin. 12: 349-353. (In Chinese.)

Zhang J., Yang T., Liu L. 2001: [Monogeneans of Chinese Marine Fishes.] Agriculture Press, Beijing, 400 pp. (In Chinese.)

Zhang J., YAng T., Liu L., Ding X. 2003: A list of monogeneans from Chinese marine fishes. Syst. Parasitol. 54: 111-130. 